\title{
Un caz rar de agenezie de venă cavă inferioară asociată cu tromboză venoasă profundă
}

\author{
Iulia Armean', Cristina Oana Mărginean ${ }^{1,2}$, Lorena Elena Melițt,, Carmen Duicu ${ }^{1,2}$ \\ ${ }^{1}$ Clinica Pediatrie I, Spitalul Clinic Judeţean de Urgenţă, Tg. Mureş, România \\ ${ }^{2}$ Universitatea de Medicină şi Farmacie, Tg. Mureş, România
}

\begin{abstract}
REZUMAT
Agenezia de $\mathrm{VCl}$ este o malformaţie extrem de rară, de cele mai multe ori descoperită întâmplător, reprezentând un important factor de risc în dezvoltarea trombozei venoase profunde (TVP) spontane la copii şi adulţii tineri.

Prezentăm cazul unui copil, de sex masculin, în vârstă de 8 ani, internat în clinica noastră pentru următoarele acuze: durere în regiunea lombară dreaptă cu iradiere paravertebrală. Din antecedentele personale patologice, menţionăm o apendicectomie recentă. La momentul internării, s-a efectuat ecografie abdominală, care a evidenţiat nefromegalie dreaptă şi a ridicat suspiciunea de agenezie de venă cavă inferioară. S-a efectuat angioCT toraco-abdominal cu substanţă de contrast, care a confirmat diagnosticul de agenezie de venă cavă inferioară şi venă iliacă comună dreaptă, tromboză venoasă la nivelul venei iliace externe drepte, venei femurale comune drepte şi venei femurale superficiale drepte. Au fost excluse diagnosticele de sindrom antifosfolipidic şi trombofilie, iar testele genetice au eliminat posibilitatea unei predispoziţii familiale. S-a instituit terapie anticoagulantă cu monitorizarea atentă a timpilor de coagulare, evoluţia fiind favorabilă.

În ciuda incidenţei foarte scăzute a acestei malformaţii, diagnosticul precoce, prompt şi corect este esenţial în ceea ce priveşte managementul şi prognosticul acestor pacienţi.
\end{abstract}

Cuvinte cheie: tromboză venoasă profundă, agenezie venă cava inferioară, copil

\begin{abstract}
Abrevieri
VCI - vena cavă inferioară

TVP - tromboză venoasă profundă

EP - embolie pulmonară

INR - international normalized ratio
\end{abstract}

\section{INTRODUCERE}

Anomaliile venei cave inferioare (VCI), cum ar fi agenezia segmentului infrahepatic sau hipoplazia VCI, au o incidență foarte scăzută, afectând un procent de $0,5 \%$ din populația generală. Agenezia de VCI este o malformație extrem de rară, de cele mai multe ori descoperită întâmplător, fiind frecvent asociată altor anomalii congenitale cum ar fi: situs inversus, malformații cardiace, polispenie sau asplenie (1). Principalele cauze care pot determina anomalii ale VCI constau în perturbarea procesului de dezvoltare embrionară a sistemului venos sau tromboza venoasă perinatală cu alterarea dezvoltării sistemului venos (3).

Anomaliile VCI reprezintă un important factor de risc în dezvoltarea trombozei venoase profunde (TVP) spontane la copii şi la adulții tineri (4).

Incidența trombembolismului venos care este definit ca TVP şi/sau embolie pulmonară (EP) a crescut semnificativ în ultimii ani, TVP fiind diagnosticată la aproximativ $1 / 200$ dintre pacienții de vârstă pediatrică spitalizați $(5,6)$. 
TVP reprezintă o patologie rar întâlnită în rândul copiilor, diagnosticarea ei fiind o provocare pentru medicii pediatri din cauza absenței simptomelor clinice specifice (7). Majoritatea copiilor care dezvoltă acestă patologie prezintă mai mulți factori de risc din cauza determinismului multifactorial al TVP (8). Incidența acesteia a crescut semnificativ datorită supraviețuirii copiilor cu patologii considerate fatale în trecut şi a tehnologiilor extrem de avansate care permit acest lucru. La copiii cu vârsta sub 15 ani, incidența este de aproximativ 5 la 100.000 de cazuri. În SUA, această patologie prezintă o prevalență între 34 şi 58 de cazuri la 10.000 de spitalizări $(10,6)$.

Studii recente susțin faptul că ultrasonografia prin compresie venoasă reprezintă metoda de diagnostic utilizată de primă intenție în cazul acestei patologii, oferind avantajul unei uşoare accesibilități, al siguranței în utilizare şi al unor costuri reduse. $\mathrm{Cu}$ toate acestea, ,standardul de aur“ în diagnosticul TVP rămâne angio-computer-tomografia $(9,11)$.

Terapia medicamentosă în cazul TVP include fondaparina şi inhibitorii direcți ai trombinei, dar cel mai frecvent este utilizată heparina cu greutate moleculară mică, warfarina sau heparina nefractionată (12).

Prezentăm un caz de TVP asociată cu agenezie de venă cavă la un copil de sex masculin în vârstă de 8 ani, cu scopul de a sublinia raritatea acestei patologii şi importanţa unui diagnostic precoce, prompt şi corect.

\section{PREZENTARE DE CAZ}

\section{Motivele internării}

Prezentăm cazul unui copil, de sex masculin, în vârstă de 8 ani, internat în clinica noastră pentru următoarele acuze: durere în regiunea lombară dreaptă cu iradiere paravertebrală. Din antecedentele personale patologice, menţionăm că, anterior spitalizării în clinica noastră, cu aproximativ 7 zile, pacientul a suferit o apendicectomie, cu evoluție postoperatorie lentă din cauza simptomatologiei descrise anterior, ridicându-se suspiciunea unei pielonefrite. Antecedentele heredocolaterale nu au fost semnificative.

\section{Examen clinic}

La momentul internării, examenul obiectiv a evidentiat următoarele elemente patologice: stare generală influențată, tegumente palide, teroase, cicatrice postapendicectomie în fosa iliacă dreaptă, abdomen dureros la palparea superficială şi profundă în hipocondrul drept şi flancul abdominal drept, lojă renală dreaptă dureroasă.

\section{Evaluare diagnostică}

Ecografia abdominală inițială a evidențiat nefromegalie dreaptă, rinichi drept cu dimensiuni de aproximativ $118 / 49 \mathrm{~mm}$, ecogenitatea corticalei crescută, cu ştergerea diferențierii cortico-medulare, fără a se putea vizualiza vena cavă inferioară, ridicându-se astfel suspiciunea de agenezie de venă cavă.

S-a efectuat angio CT toraco-abdominal cu substanţă de contrast, care a confirmat şi a completat rezultatul ecografiei abdominale, după cum urmează: ficat neomogen din cauza prezenței în segmentul 8 a unei plaje triunghiulare în care apar tulburări de perfuzie consecutive trombozei ramurii portale, tromb în vena portă, în imediata vecinătate a confluentului spleno-mezenteric, cu diametru de 7/4 $\mathrm{mm}$, rinichi drept mărit în volum, cu nefrograma uşor neomogenă, posibil din cauza drenajului venos care nu poate fi identificat, vena cavă absentă sau posibil trombozată, drenajul venos al rinichiului stâng prin vena spermatică stângă, apoi drenând în venele paravertebrale, venă azygos şi hemiazygos (Fig. 1, 2, 3).

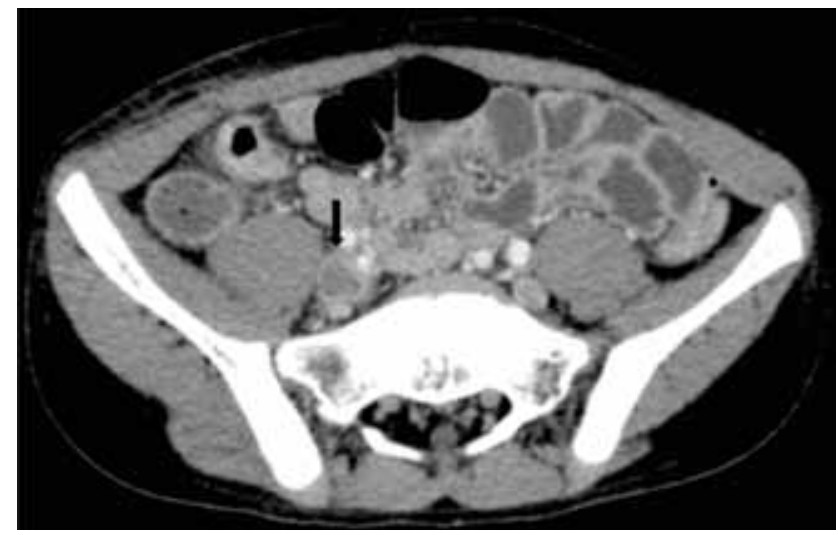

FIGURA 1. Tromboză venă iliacă dreaptă

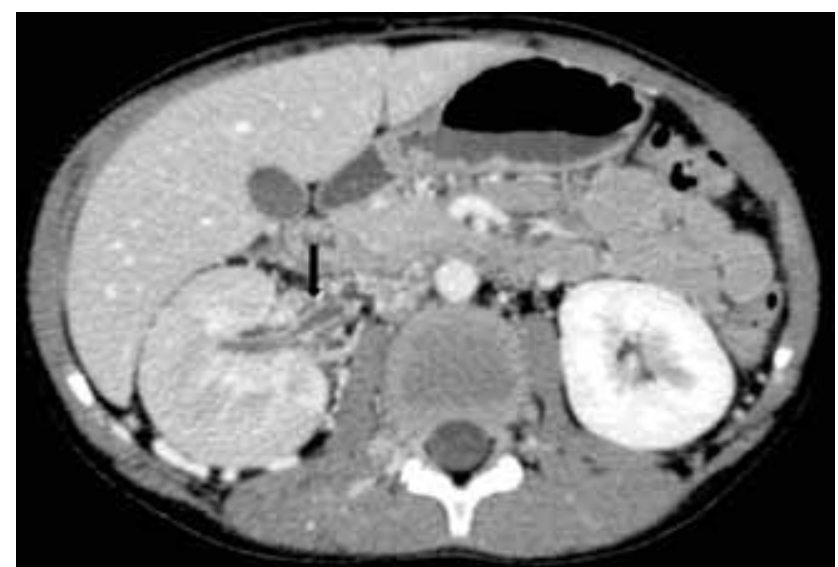

FIGURA 2. Tromboză venă renală dreaptă, agenezie venă cavă inferioară 


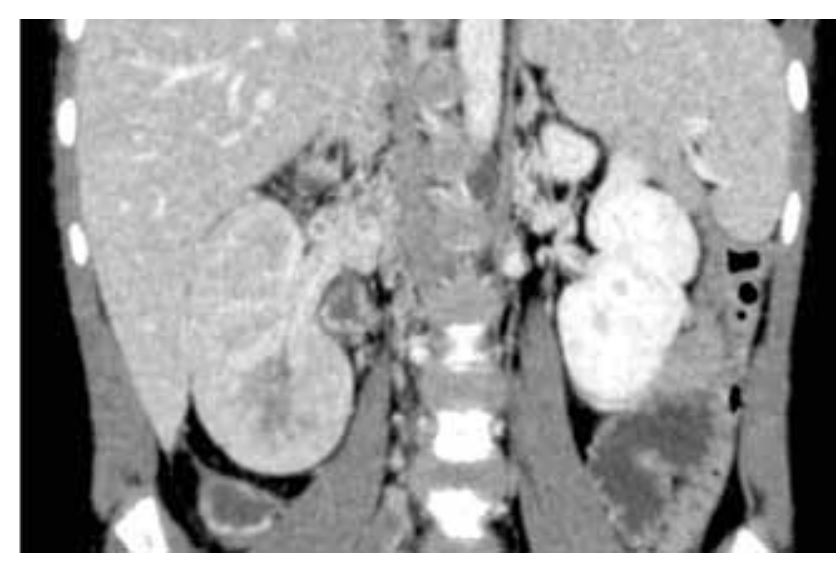

FIGURA 3. Asimetrie de încărcare renală, cu persistența iodofiliei corticalei renale drepte

Ecografia Doppler venoasă a evidențiat absența venelor suprahepatice, venei cave inferioare, venei iliace comune drepte, tromboza venei iliace externe drepte, necomprimabilă, cu imagini hiperecogene intraluminal, tromboză venă femurală comună dreaptă, necomprimabilă, cu imagine hiperecogenă intraluminală, şi tromboza venei femurale superficiale drepte.

Pentru excluderea diagnosticului de sindrom antifosfolipidic, s-au efectuat următoarele analize de laborator cu rezultate în parametri normali: anticorpi anti beta 2 glicoproteina $\operatorname{IgM}(1,3 \mathrm{U} / \mathrm{ml})$, anticorpi anti cardiolipina IgM (1,2 MPL-U/ml), anticoagulant lupic absent. Testele genetice nu au arătat mutații la nivelul factorului V Leiden (A506G) sau al factorului II (gena protrombinei G20210A). De asemenea, pentru excluderea trombofiliei, s-au efectuat teste pentru antitrombina III, factorul von Willebrand, proteina $\mathrm{C}$, proteina $\mathrm{S}$ şi homocisteina, care au fost în limite normale.

\section{Evaluare terapeutică}

După stabilirea diagnosticului de agenezie de venă cavă inferioară şi venă iliacă comună dreaptă, tromboză venoasă la nivelul venei iliace externe drepte, al venei femurale comune drepte şi venei femurale superficiale drepte, s-a instituit terapie anticoagulantă cu heparină cu greutate moleculară mare, cu monitorizarea atentă a timpilor de coagulare. Ulterior, s-a introdus terapie cu heparină cu greutate moleculară mică, cu evoluţie favorabilă. Pacientul a fost externat în stare generală bună, cu recomandări de terapie anticoagulantă cu acenocumarol, cu monitorizarea atentă a INR-ului şi profilaxie cu ciorapi elastici.

\section{DISCUŢII}

VCI prezintă o embriogeneză complexă şi bine documentată. Anatomic, aceasta este compusă din
4 segmente: hepatic, suprarenal, renal şi infrarenal $(13,14)$. Malformațiile VCI pot fi reprezentate de: malrotația şi poziţionarea pe partea stângă a VCI, drenarea VCI în vena azygos intratoracică, venă renală stângă circumaortică, duplicația VCI cu traiect intratoracic normal sau duplicația VCI cu drenare în vena azygos şi hemiazygos şi absența segmentului infrarenal al VCI sau absența totală a acesteia (15). Unii autori susțin faptul că absența VCI poate fi un rezultat al trombozei perinatale sau al trombozei intrauterine, care duce la obliterare, iar apoi la resorbție $(13,14)$. Dacă segmentul infrarenal al VCI nu prezintă o dezvoltare normală, venele iliofemurale vor drena în venele azygos şi hemiazygos prin colaterale anterioare paravertebrale. Din cauza diametrului mult inferior al acestor colaterale comparativ cu cel al VCI, este evident faptul că acestă cale colaterală poate duce la stază venoasă cronică şi, ulterior, la tromboza extremităţilor inferioare (13). Mecanismul menționat anterior este reliefat şi în cazul pacientului nostru.

În timpul embriogenezei, metanefronii drepți drenează în VCI. Astfel, agenezia VCI poate afecta dezvoltarea rinichiului drept, cu hipoplazie de rinichi drept sau chiar agenezie. Unii autori numesc această patologie sindromul KILT, care asociază anomalia VCI, a rinichiului drept şi tromboza extremităţilor inferioare $(1,11,13)$. În cazul descris mai sus, pacientul prezintă nefromegalie, diagnosticul de sindrom KILT neputând fi susținut.

TVP reprezintă o patologie severă în rândul copiilor, având o importanță clinică majoră din cauza ratei crescute de mortalitate şi morbiditate. Diagnosticarea corectă, promptă şi precisă a TVP este de o importanţă critică, date fiind şi riscurile asociate terapiei acestei patologii $(7,16-18)$. Dintre factorii de risc care duc la dezvoltarea TVP menționăm: factorii genetici, traumatismele, intervențiile chirurgicale, neoplaziile, cateterele venoase centrale, anomaliile venoase, inflamația cronică şi sepsisul $(8,11,17,18)$. În cazul pacientului nostru, cu toate că nu prezintă risc genetic, subliniem faptul că, anterior spitalizării în Clinica de Pediatrie, acesta a suferit o apendicectomie care a necesitat imobilizare prelungită la pat şi, de asemenea, pacientul asociază o anomalie vasculară rară, agenezie de VCI şi venă iliacă comună dreaptă. Astfel, toți aceşti factori cumulați au dus la apariția TVP.

Este cunoscut faptul că anomaliile congenitale ale VCI reprezintă un factor de risc în dezvoltarea TVP în cazul adulților tineri, însă prevalența acestor anomalii în rândul pacienților pediatrici cu TVP spontană nu este foarte clară. Studii recente evidențiază faptul că TVP tinde să aibă o predominanță 
mai crescută la pacienții de sex masculin, cu o incidență crescută la vârsta de adult tânăr (19) şi la copii $(4,11,15,18)$. Acest fapt este susţinut şi de studiul nostru de caz, care evidențiază prezența TVP la un copil de sex masculin în vârstă de 8 ani.

În cazul pacienților cu TVP ca o consecință a ageneziei de VCI, nu există un tratament standard. TVP este o patologie rar întâlnită în rândul copiilor, motiv pentru care nu este elaborat un protocol terapeutic clar pentru această condiție. Cu toate acestea, heparina cu greutate moleculară mică este preferată în tratamentul copiilor care prezintă TVP. Unii autori recomandă cel puțin 6 luni de terapie anticoagulantă, dar, de cele mai multe ori, terapia anticoagulantă este necesară pe toată durata vieții, chiar şi în ciuda excluderii unei trombofilii, cu scopul de a preveni recurențele (11). În mod similar, în cazul pacientului nostru, tratamentul a fost ghidat în funcţie de evoluția clinică şi de aspectul ecografiilor seriate, fiind necesară terapie anticoagulantă pe toată durata vieții din cauza anomaliei vasculare asociate. Probabil că studii ulterioare vor contribui la stabilirea prognosticului pe termen lung al pacienți cu TVP şi la elaboarea unui protocol terapeutic pediatric optim al TVP secundare malformațiilor vasculare.

\section{CONCLUZII}

Anomaliile congenitale ale VCI reprezintă un factor de risc important în dezvoltarea TVP a extremităţilor inferioare în cazul copiilor şi adolescenţilor. În lipsa antecedentelor heredocolaterale semnificative, a unei trombofilii sau a unei posibile mutații genetice, cazul prezentat mai sus a cumulat factori pro-coagulanți cum ar fi: staza venoasă cronică, întoarcerea venoasă deficitară din cauza imobilizării prelungite postapendicectomie şi hipertensiunea venoasă din cauza absenței trunchiurilor venoase principale, ducând iminent la apariţia TVP a extremităților inferioare. 